\title{
Keynote presentation: strategic keys
}

NFAIS Executive Director is joined by the official representatives of participating sister societies to discuss strategic issues

Speakers:

Rick Bowes

Bonnie Carroll

Mary Case

Eugene Garfield

Pat Harris

Tom Hogan

Clifford Lynch

David Russon

Georg Schultheiss
Society for Scholarly Publishing

CENDI

Association of Research Libraries

American Society for Information Science

National Information Standards Association

Association of Information and Dissemination Centers

Coalition for Networked Information

International Council for Scientific and Technical Information

EUSIDIC

\section{Strategic Keys}

This year's NFAIS conference was a "meeting of the minds" between NFAIS and ten of its sister societies to discuss information issues of critical importance to all of these constituencies. Rather than a single-speaker Keynote Address, the conference brought together representatives from each society on a common platform to offer a watchword, catchword, keyword, or guiding phrase of strategic importance.

The words were:

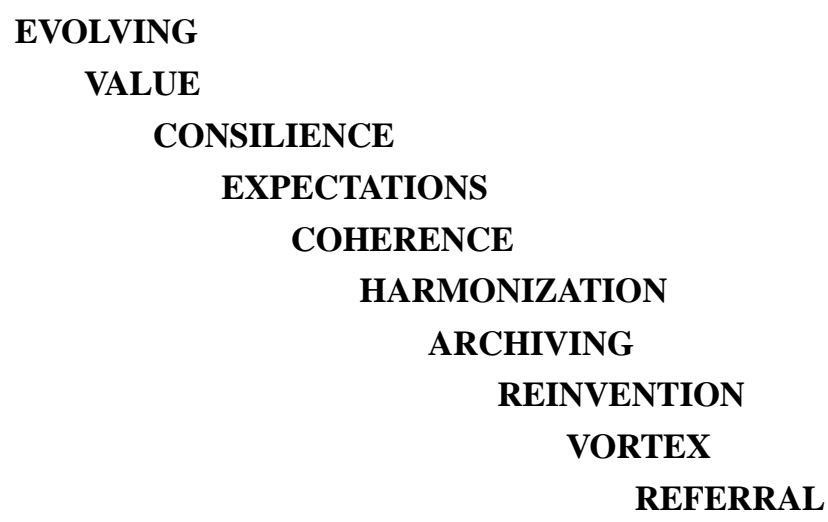

Mary Case, Director of the Office of Scholarly Communication, Association of Research Libraries (ARL), says "we are living in a time of great transition". Thus her keyword of the day is EVOLVING. She mentions several parties to the evolution, among them technology, law, user behavior, and economics. She also talks of the mandate to "embrace ambiguity" in changing times. 
Speaking on behalf of the Association of Information and Dissemination Centers (ASIDIC), Tom Hogan, President of Information Today, Inc., calls VALUE his guiding principle. He asks: what is the value of information? Is it the price we put on information? Is it the buyers' or potential buyers' perception of its value? Or is there some intrinsic value to information itself?

Leave it to the eminent Eugene Garfield, Chairman Emeritus of the Institute for Scientific Information and the inventor of the ISI citation index products, to introduce a new word to our vocabulary: CONSILIENCE. Dr Garfield is also President-Elect of ASIS. Consilience was once achieved by a unified index to science, and is today exemplified in a service such as the Web of Science. But in a world where traditional publication forms are transforming into "infinitely malleable electronic forms", Garfield sees the need to better reconcile all the multi- and interdisciplinary interests prevailing on the Net.

Bonnie Carroll, President of Information International Associates, Inc. and the Secretarial Director of CENDI (a federal government interagency group of senior STI managers), reminds us that EXPECTATIONS drive the market - the rise of Internet stocks being a prime example. One guiding expectation should be that "the electronic world can't be dealt with as a linear extension of the print world".

Cliff Lynch, Director of the Coalition for Networked Information (CNI) put COHERENCE on the agenda, which he sees as an increasing issue for users, consumers, and institutions of all kinds. In the networked environment, there is a great fragmentation of information, and of how information is delivered. This fragmentation creates a need to restructure roles and to develop technology that tries to bring this new world back into some sort of coherent form for people who want to navigate it.

Georg Schultheiss, Chairman of the EUSIDIC Council, sees HARMONIZATION in a transatlantic and global business dialog as the imperative for the day. Dr Schultheiss is also Director of FIZ Karlsruhe. There are dramatic differences between European and North American usage of the Internet. The European Commission has set up a Global Business Dialog initiative to harmonize issues such as: taxation, tariffs, intellectual property rights protection, encryption, authentication, and data protection.

"Science depends upon having a record of past science", says David Russon, Deputy Chief Executive of The British Library and ICSTI's immediate Past President. This statement explains why ARCHIVING is the watchword coming from The International Council for Scientific and Technology Information (ICSTI). Russon asks where we will find electronic publications of today in 50 years. Who will be responsible for the archives? How much will it cost? What standards are going to be used? These questions need to be answered to ensure that the digital scientific record is maintained in the future.

REINVENTION resounds as the keyword of the times for Pat Harris, Executive Director of the National Information Standards Organization (NISO), who says that we are all challenged to redefine ourselves, our missions, and reconsider what we are doing. Partnership is one strategy that will have to be used in the reinvention process.

Rick Bowes' - President of the Society for Scholarly Publishing (SSP) and of Bowes \& Associates, Inc. - unique "spin" on keywords put VORTEX on the map. Vortex companies are what Bowes calls "neutral market makers trying to bring end users and publishers together where information is difficult to find and end users and publishers are both plentiful and fragmented". He also compares the impact of the Internet on scholarly publishing to a vortex tornado spinning out of control, with many pieces ripping loose as the Net gains momentum.

Some questions spinning off of the vortex are: who are the users, what are the pricing models, what is the product, what is the fundamental value proposition, and what will it be like after the storm passes. Dick Kaser, Executive Director of NFAIS, provides one piece of the answer (his mantra): "The value of information is in its ability to be reused". His catchword is REFERRAL, and he advises that a good strategy would be to get people to refer others to your site and your content. 
Indeed, a recent editorial published on NUA INTERNET SURVEYS (a survey report service on the Net) illustrates Kaser's point about the power of referral: "While the Web allows anybody and everybody to publish whatever they like, the exponential growth of documents on the Web mean that not everything that is published will be read. There is little value in publishing a document if nobody ever sees it.

"The value of information is in its structure. Data become information through the process of structure and publication. Once published, the information must then be found. The Internet relies on search engines to put structure on the thousands of documents published every day."

"When the average person is presented with one million returns on a given query, $\mathrm{s}(\mathrm{he})$ will sift through ten of those results and then give up. Some search engines return results pages with the most trafficked sites at the top of the page. There is an obvious need for this kind of search facility; in the face of complexity, the average person would rather that the choice is made for them. The myth of the most popular Web sites on the Net is perpetuated by repeated delivery of new users to "the most trafficked sites", and the Internet shrinks."

"... In an environment where search engines are owned by media companies with obvious vested interests, the objective indexing capabilities of search agents has to be questioned."

Web look-ups: ARL: www.arl.org

ASIDIC: www.asidic.org

ASIS: www.asis.org

CENDI: www.dtic.mil/cendi

CNI: www.cni.org

EUSIDIC: www.eusidic.org

ICSTI: www.icsti.org

NFAIS: www.pa.utulsa.edu/nfais.html

NISO: www.niso.org

SSP: www.sspnet.org 